\title{
Methodological Approaches to Assess the Stability and Global Competitiveness of the Regions under the Macroeconomic Instability Conditions
}

\author{
Marat Rashitovich Safiullin
}

Kazan Federal University, Center of Advanced Economic Research Academy of Sciences of the Republic of Tatastan, Kazan, Kremlevskaya, 18, 420008; Kazan, Ostrovskogo 23, 420111

Leonid Alekseevich Elshin

Kazan Federal University, Center of Advanced Economic Research Academy of Sciences of the Republic of Tatastan, Kazan, Kremlevskaya, 18, 420008; Kazan, Ostrovskogo 23, 420111

Mariya Igorevna Prygunova

Center of Advanced Economic Research Academy of Sciences of the Republic of Tatastan, Kazan, Ostrovskogo 23, 420111

Doi:10.5901/mjss.2015.v6n3s2p524

\section{Abstract}

Modern conditions of managing are characterized by the deep level of integration of national economic systems. Special relevance to the considered processes of adaptation of regional economic systems to "external" impulses is given by the introduction in 2012 to Russia in the WTO and accumulation in recent months of intensity in the relations of the Russian Federation with a certain part of the world community. In work the task of approbation of the methodical principles of taking note of external "impulses" on an index of business activity of the region (IDA) on the example of two regions of the Volga Federal District is set: Republic of Tatarstan and Ulyanovsk region.

Keywords: regional development, external shock "impulses", forecasting, index of business activity, sustainable development of the region.

\section{Introduction}

The dynamics of sustainable development of the regions, and therefore their competitiveness degree at the national and international level, are to a large extent determined by the receptivity of certain types of economic activities, conducting their business in one or other territory, to the external "impulses", generating the structure and nature of the expectations of economic agents. In this regard, it seems reasonable to assess the competitiveness of FEA (in terms of their receptivity to externals) in the interregional section. This type of analytical works will largely characterize the stability of development of certain types of economic activities in the region, including with respect to similar factories located in neighboring regions. This, in its turn, will allow at the early stages of external influence on the national economy to understand the prospects of development of the industrial potential of the regions. Moreover the proposed structural and logical analysis of the regional FEA receptivity to the external "impulses" favors the scenario modeling and forecasting in the med-term perspectiveof dynamics of the growth rate of the regional economy as a whole and its individual components by developing a single-step algorithm for accounting the changes in the region business activity index as one of the key indicators characterizing the economic agents expectations.

The research of "nature" of the external "impulses" emergence, the depth and extent of the consequences resulting from their impact on the national and regional economic system requires a detailed study. Moreover the fact, that the structural changes in various types of economic activities form the basis of the macroeconomic effect, expressed in changes in the volume and dynamics of GDP, is important. This, in its turn, will determine the character and structure of the development of regional economic systems, each of which is unique in the context of reproductive structure [10].

A very important aspect in the analysis and assessment of the external "impulses" effect on the regional economic development is the systematization and division of FEA into two groups:

1. Types of economic activities, in the sales volume structure of which export supplies are dominated (for example, chemical production); 
2. Types of economic activities oriented to the domestic market (production of food stuff, including drinks and tobacco, textile and sewing production)

For example, if you understand an external "impulse" as the liberalization of foreign trade (as a result of entering of a country to WTO), then the character of changes occurring in a certain type of economic activity will depend on the group which it belongs to. This is explained by the fact that export-oriented and import-substituting FEA have different directions in getting the relevant effects.

If you classify some sanctions of a certain number of the international community, expressed, for example, in restriction of exports, of access to financial markets, of the transfer of new technologies, as external "impulses", in this case, the effects will have a one-sided negative nature, regardless of belonging to the FEA groups previously selected. It should be noted that external sanctions form a new organizational operating environment for corporations, largely limiting their investment activity and, as a result, predetermining downturn of the economic and operating activities. However, sectoral sanctions may restrict the volume of imports and foreign advanced technologies, which can create an additional impulse for the development of domestic enterprises producing import-substituting goods and services.

On the basis of the foregoing, the authors have developed a structural and logic simulation scheme of influence of external "impulses"on the development of regional economic activities[20]:

1. Identification of the external «impulses»;

2. Grouping of regional FEAon the basis of their foreign markets orientation and the response to external "impulses";

3. Development and determination of exogenous factors affecting the endogenous parameters of development of certain types of economic activities;

4. Development of economic-mathematical model that determines the correlation between exogenous and endogenous factors of the development of FEA;

5. Scenario modeling of exogenous parameters, including those which determine the value of the "shock" effects during the current and long periods of time;

6. Forecast of development of individual FEA and its projection on the general economic indicators of economic development of the region.

\section{Methods}

The logic of the selection of index characterizing the expectations of economic agents in developed model of external «impulses» impacton the development of industrial FEA looks as follows. Expectations are central link in the process of determination of prospective development plans developed in the corporative sector. Any actions of economic agents, resulting in corrections of the volume of the produced and shipped products, follow primarily their expectations. [14] If the expectations of economic agents are adaptive, the current volumes of production and deliveries of products will be to a large extent determined by the past values of their growth rate. Modeling of expectations was carried out on the basis of the indicator assessing the business activity of the region.

At the same time the authors suggest using composite index of business activity of the region as the indicator allowing tracking the state of business activity on a regular monthly basis. Four main indicators are included as the components of this indicator: production, financial sector, the resource base of the economy, consumer market. Within each category the weights of its constituent indicators are determined; each category, in its turn, has its own weight in the integral index of business activity. A set of indicators included as a compound of the index, is determined on the basis of the factors affecting the formation of the economic conjuncture and the dynamics of its development [15].

The modeling process consists in determination of the monthly indexes of business and economic activity of the region and its individual economy sectors. Application of this method enables to reveal the intermarket interactions, to determine the structure of the occurrence of economic crises, as well as to identify the reaction of economic agents to the external "impulses".

Let's imagine a logical model of development of business activity indexes of the region (BAI) [1] and its approbation on the example of two regions of the Volga Federal District: the Republic of Tatarstan and the Ulyanovsk region. When calculating the BAI the macroeconomic data provided by official statistical agency are used.

The method, used in this study, is based on the application of the factor approach, i.e. revealing a set of factors affecting the level of socio-economic development of the region. In this approach, first the analyzed factors are combined into sub-indexes, which are the sum of the many weighted average assessments for the analyzed components. On the basis of this system of indicators characterizing the certain types of activities, and the index method,the integral (composite) or a composite index is calculated - "Business activity index", which determines the level of business activity 
of the object being assessed as a whole.

Let's imagine the conceptual algorithm of constructing of composite anticipatory index of business activity of the region in the form of a flow diagram (Figure 1).

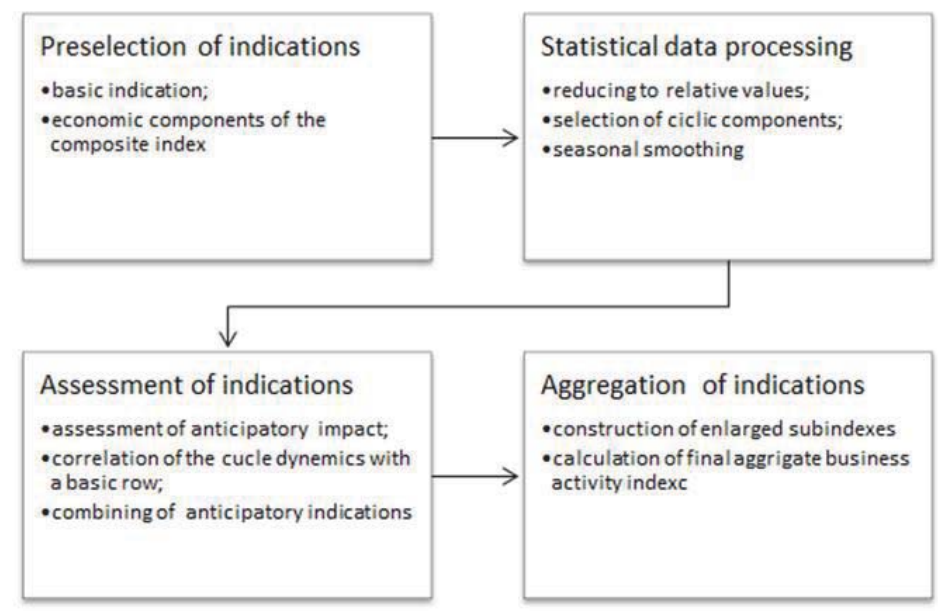

Figure 1. Stages of construction of the aggregate integrated business activity index of the region

The modeling process consists in determination of the monthly indexes of business and economic activity of the region and its individual economy sectors. Application of this method enables to reveal the intermarket interactions, to determine the structure of the occurrence of economic crises, as well as to identify the reaction of economic agents to the external "impulses".

Let's present a logical model of development of business activity indexes of the region (BAI) [1] and its approbation on the example of two regions of the Volga Federal District: the Republic of Tatarstan and the Ulyanovsk region. When calculating the BAI the macroeconomic data provided by official statistical agency are used.

As noted above, the ideal reference indicator for the assessment of business activity is GDP. For the Republic is domestic regional product (DRP) respectively.

However, as the official statistical body of Tatarstan - Tatstat - officially provides according to the GRP indicator only quarterly and annual statistical reports, this macroeconomic indicator cannot be used as a base (reference) one. Accordingly, it is necessary to choose another indicator, the dynamics of which is very similar to the GDP [3].

Focusing on the international and domestic experience of construction ofaggregate indexes of anticipatory indicators of business activity, we analyzed the index of industrial production (IIP) acting as such indicator that would characterize the economic activity of the Republic of Tatarstan.

The analysis of time series of GDP and IIP indicates that these series are strongly correlated with each other. This gave us opportunity to use the index of industrial production as the basic indicator in assessing the business activity of the Republic of Tatarstan due to the presence of official monthly statistics of this indicator [2].

To form a system of economic components, which shallfinally form the aggregate anticipatory index, it was necessary to determine the indicators which are characterized by anticipatory character of dynamics relative to a reference indicator from a great many of possible indicators affecting the dynamics of GDP.

Since the purpose of our study is to construct an aggregate indicator of business activity, preceding the general economic dynamics, we did not consider the indicators that are initially not anticipatory, but rather synchronous or retarded (for example, retail sales).

While making the list of the economic components suggested for inclusion in the aggregate anticipatory business activity index of the region, we focused on the following aggregated macroeconomic data (categories): production, financial sector, the resource base of the economy, the consumer market. The data obtained from the companies are accumulated into the categories of "Entrepreneurial assessment and expectations." Within each category the weights of its constituent indicators are determined; each category, in its turn, has its own weight in the integral index of business activity.

In the general form the integral index of business activity is the sum of four main components: the three weighted indexes of various industry groups of the economy (the capital change index, resource and production indexes) as well as 
stock index, reflecting the tendency of development of the securities market.

\section{Results}

In the general form the integral index of business activity is the sum of four main components: the three weighted indexes of various industry groups of the economy (the index of changes in the capital, resource and production indexes) as well as stock index, reflecting the tendency of development of the securities market.

Determination of the weight coefficients of each component of theaggregate index was based on the performed cross-correlation analysis. The analyzed lag was from 3 to 8 months. The weights were calculated in proportion to the obtained maximum correlation coefficients (Table 1 - 2).

Table 1. Cross-correlation analysis of weight coefficient, composing the aggregate anticipatory business activity index of the Republic of Tatarstan

\begin{tabular}{|c|c|c|}
\hline Name of subindex & Value of assigned weight & Correlation coefficient \\
\hline Capital change index & 0.34 & 0.76 \\
\hline Stock index & 0.23 & 0.50 \\
\hline Resource index & 0.31 & 0.69 \\
\hline Production index & 0.12 & 0.26 \\
\hline
\end{tabular}

Table 2. Cross-correlation analysis of weight coefficient, composing the aggregate anticipatory business activity index of the Ulyanovsk Region

\begin{tabular}{|c|c|c|}
\hline Name of subindex & Value of assigned weight & Correlation coefficient \\
\hline Capital change index & 0.28 & 0.61 \\
\hline Stock index & 0.20 & 0.49 \\
\hline Resource index & 0.24 & 0.51 \\
\hline Production index & 0.28 & 0.36 \\
\hline
\end{tabular}

The use of these methodological approaches enables to make the conclusion that, in the Republic of Tatarstan, as well as in the Ulyanovsk region in the period from 2007 to 2013 multidirectional tendencies in the dynamics of business activity of economic entities were observes. During the period of from 2010 till beginning of 2013 the aggregate anticipatory index of business activity in these regions demonstrated a positive trend in general, which indicated the strengthening of economic growth expectations. But by the end of the second quarter of 2013 there was a recession in its level. And since September of 2013, dynamics of the level of business activity index began to demonstrate a significant decline.

However, it must be noted that the index of business activity in the Republic of Tatarstan for the great number of time periods were higher compared to similar values characterizing the expectations of economic agents of the Ulyanovsk region. Apparently this is due to the structural and institutional characteristics causing the economic growth in the studied regions. For example, the value of the weight coefficient for production index is higher for the Ulyanovsk region and for capital change index and for the stock index - it is higher for the Republic of Tatarstan. This may indicate the dominance in the economic development of the Republic of Tatarstan of the institutions of deeper integration into international economic relations and a higher degree of openness of the economy and, therefore, its increased dependence on external market factors. However, a higher level of the weight coefficient for the production index in the Ulyanovsk region can say that when forming their expectations the economic agents of this region are increasingly oriented on the physical indicators of the organizations (for example, the volume growth rate of shipped goods of own production, trade stocks, etc.). 


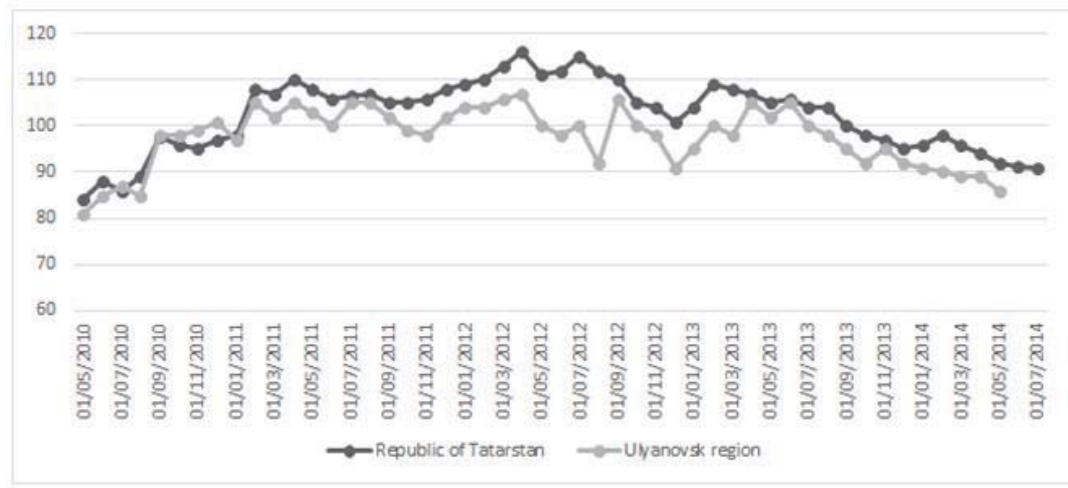

Figure 2. The dynamics of the aggregate anticipatory index of the Republic of Tatarstan and the Ulyanovsk region

Taking into account that PAI is built on the basis of accounting of the conjunctural changes in the external and domestic markets it can be stated with confidence that the developed model of the influence of external "impulses" impact on the development of certain types economic activities in certain regions analyzes the interconnection between the external and domestic markets of the produced products.

The indicator, characterizing the growth rate of the products production volumes, is selected as an endogenous parameter.

\section{Discussion}

Thus, in the work the task is set to approbate the methodological principles of accounting of the external "impulses" impact on the development of individual regional FEA and on their basis to determine the level of liability to external "impulses" of regional economic systems in general.

The selection of criteria for the construction of economic and mathematical model is performed from the available statistical base. The system of indicators does not contain expert indicators or the indicators based on the results of surveys of economic and business entities.

Further we present the stated concept of the external "impulse" impact on the development of regional FEA in the context of industrial types of economic activities of the Republic of Tatarstan and the Ulyanovsk region. Thus, initially, the modeling process will be based on the correlation analyze. This approach differs from ones we previously published [20] in terms of the transition from modeling of multiple regression equations containing a set of exogenous variables, including PAl, to measurement of the impact of the index dynamic assessing closeness of the connection between the expectations of economic agents of the region (PAI) and the growth rate in the industrial sectors of the regional economy.

The results of correlation analysis, based on the measurement of closeness of the connection between the studied indicators and one constructed on the basis of monthly data in the range of 2009-2014 are presented in the Table 3. The whole sample includes 65 observations for each type of economic activity of the Republic of Tatarstan and the Ulyanovsk region, belonging to the industrial sector.

Table 3. Values of correlation coefficients assessing closeness of the connection between the dynamics of the growth rate of the aggregate index of business activity and the growth of industrial sectors

\begin{tabular}{|c|l|c|c|}
\hline \multirow{2}{*}{ № } & \multirow{2}{*}{ Name of the studied indicator } & \multicolumn{2}{|c|}{ Correlation coefficient value } \\
\cline { 3 - 4 } & Industrial production & 0.609 & 0.724 \\
\hline 1 & Extraction of minerals & 0.399 & 0.297 \\
\hline 3 & Manufacturing activities & 0.671 & 0.769 \\
\hline 4 & Production and distribution of electric power, gas and water & 0.365 & 0.616 \\
\hline
\end{tabular}

The results of correlation analysis show the heterogeneity of influence of business activity conjuncture on various economy sectors of the studied regions relating to industrial profile. As we can see from the presented calculation data (Table 3) the level of closeness of the connection between the growth rates of industrial production and the dynamics of the business activity index takes very high values. At the same time, this connection is much differentiated and takes 
virtually unified character depending on the types of industrial productions. Thus, the results of the analysis show that, in such sectors as "Extraction of minerals" and "Production and distribution of electric power, gas and water" the impact of expectations of economic agents on the dynamics of the growth rate of industrial production is quite limited, which well stayswithin the general paradigm of the theory of utility and consumption of goods. [14]

The highest level of connection between the studied indicators is observed in the manufacturing industry. Based on this we then try to assess the impact of changes in the expectations of economic agents on the development of this very sector of the economy in the regions we consider.

The basis of the structural and logical model assessing the level of the connection between the studied parameters in the manufacturing industry is formed by the foregoing econometric approach; we presented above, as well as in the works published previously [13]. It is based on a method that reveals the interconnection between the dynamics of growth of industrial economy sectors and their rate in the previous periods, as well as growth rates of the values of the business activity index of the region.

In our opinion the evaluation of the coefficients, when the factor assesses the expectations of economic agents, is extremely important and informative. So, if we calculate these values in the context of many individual types of economic activities of the industrial sector of the region it is possible to determine the degree of their response to the external "impulses" at a high degree of probability. Thus, in fact, it is possible to determine the level of competitiveness and stability of development of studied types of economic activities and the region in general and to predict their further development, taking into account shock impulses formed now and in the future [13].

As an example, this article presents ratable calculations of main parameters of the econometric model, determining the interconnection between the growth dynamics of the chemical industry of the Republic of Tatarstan and the external "impulses".

$P=89,05+0,105 P(-1)+0,083 \operatorname{IDA}(-2)\left(R^{2}=0,7821\right)$,

Where $P$ is the growth rate of chemical production (smoothed series), IDA is the growth rate of the free business activity index of the region.

Table 4. Characteristic of the parameters of the statistical significance of the econometric equation assessing the dependence of the dynamics of production volumes of the chemical industry of the Republic of Tatarstan on the external "impulses"

\begin{tabular}{|c|c|c|}
\hline & Coefficients & t-statistics \\
\hline Y-cross. & 89.05 & 2.2301 \\
\hline P (-1) & 0.105 & 2.1683 \\
\hline IDA (-2) & 0.083 & 1.2508 \\
\hline
\end{tabular}

Similar calculations were carried out for other types of economic activities of manufacturing industry of the Republic of Tatarstan and the Ulyanovsk region (Table 5).

The results of the assessments of coefficients of exogenous factors, assessing the elasticity of the change in the growth rate of individual industrial productions as a result of vibrations of the aggregate index of business activity are presented in the Table 5 and Figure 3.

Table 5. Values of the coefficients of the factor, assessing the expectations of the economic agents

\begin{tabular}{|l|l|c|c|c|c|}
\hline \multirow{2}{*}{$№$} & \multirow{2}{*}{ Type of economic activity } & \multicolumn{2}{|c|}{ The Republic of Tatarstan } & \multicolumn{2}{|c|}{ the Ulyanovsk region } \\
\cline { 3 - 5 } & $\begin{array}{c}\text { Value of the } \\
\text { coefficient }\end{array}$ & $\begin{array}{c}\mathrm{t} \text {-statistics } \\
(\mathrm{p}=0.05)\end{array}$ & $\begin{array}{c}\text { Value of the } \\
\text { coefficient }\end{array}$ & $\begin{array}{c}\mathrm{t} \text {-statistics } \\
(\mathrm{p}=0.05)\end{array}$ \\
\hline 1 & Production of foodstuff, includingdrinks and tobacco & -0.035 & 1.256 & -0.056 & 2.052 \\
\hline 2 & Production of oil products & -0.041 & 2.567 & 0.032 & - \\
\hline 3 & Processing of wood and production of products from a tree & 0.048 & 0.964 & 0.073 & 1.298 \\
\hline 4 & Pulp and paper production; publishing and printing activity & 0.05 & 3.598 & 0.041 & 6.214 \\
\hline 5 & Production of electrical equipment, electronic andoptical equipment & 0.068 & 1.501 & 0.082 & 2.974 \\
\hline 6 & Production of rubber and plastic products & 0.075 & 5.215 & 0.072 & 2.549 \\
\hline 7 & Chemical production & 0.083 & 1.251 & -0.039 & 1.905 \\
\hline 8 & Metallurgical production and production of finished metal products & 0.095 & 1.659 & 0.031 & 4.214 \\
\hline 9 & Production of cars and equipment & 0.124 & 2.981 & -0.018 & 1.199 \\
\hline 10 & Production of vehicles and equipment & 0.132 & 6.328 & 0.146 & 1.564 \\
\hline 11 & Leather manufacture, production of leather products and footwear & 0.142 & 2.012 & 0.046 & 3.520 \\
\hline 12 & Textile and sewing production & 0.156 & 3.409 & 0.024 & 4.128 \\
\hline
\end{tabular}




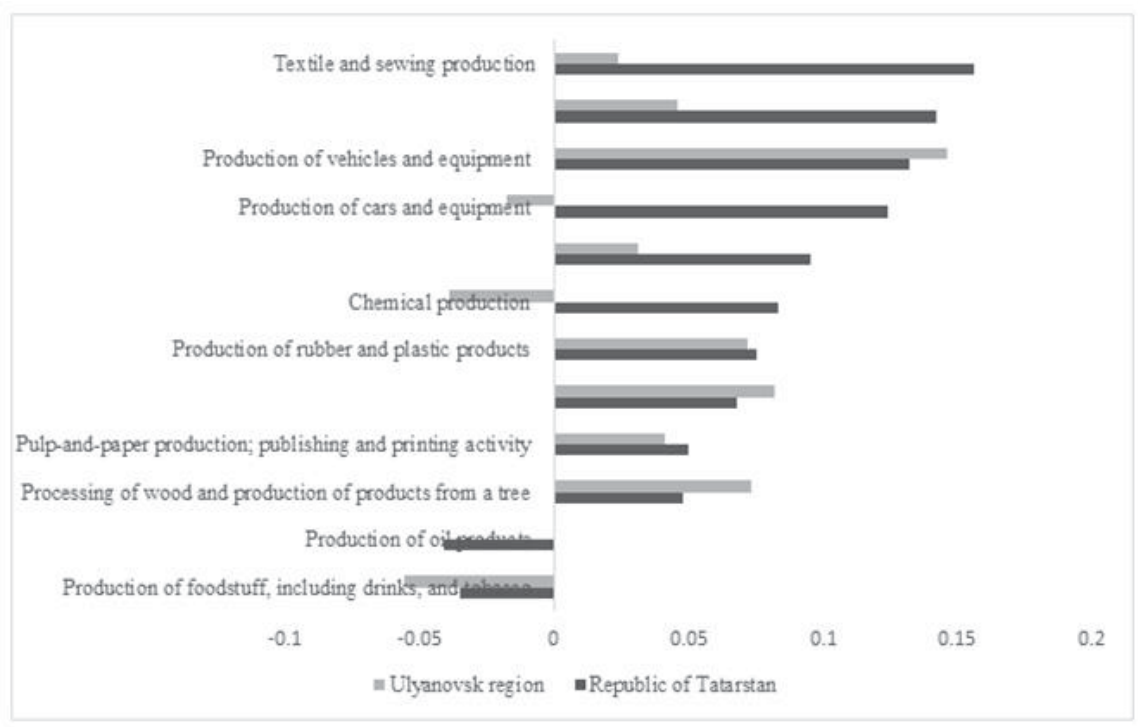

Figure 3. Comparative analysis of the values of the coefficients of the factors, assessing the economic agents' expectations in the Republic of Tatarstan and the Ulyanovsk region.

\section{Conclusions}

The calculation results show that, in the structure of industrial production there is no uniformity of response to changes in business activity in the region. A number of industrial productions havestrongly marked character depending on the response of economic agents to certain "shock" demonstrativeness, while a number of other industries have insignificant values of coefficients of elasticity, which indicates a weak character of receptivity to various external manifestations determining the dynamics of medium-term perspective.

If you carry out the comparative analysis of the competitiveness of FEA in terms of two studied regions in the context of their sustainable development under the condition of external "impulses", then we can say that in most cases, more sustainable character of development is demonstrated by the industry of the Ulyanovsk region. For example, among twelve analyzed economic activities related to the industrial profile of the economy of the studied regions, only four of them (the production of vehicles and equipment, production of electrical equipment, electronic and optical equipment, processing of wood and production of products from a tree and production of food stuff, including drinks and tobacco) demonstrated a greater level of elasticity of reaction to changes in expectations of economic agents regarding the same productions, located in the territory of the Republic of Tatarstan.

Possible reasons of "distortions" in the sustainability of development of the same FEA located in the territories of different regions may be determined based on the following set of factors:

1. The range of activity of the studied types of economic activities;

2. Focus on internal and external markets;

3. The effectiveness of the financial system of enterprises, determining their financial stability

4. The level of integration of economic entities in the system of international markets and so on.

The study of the listed factors in the context of their influence on the receptivity of the industrial economy sector of the regions to external influence requires special attention and additional assessments, which is not the subject of the study of this work and will be reflected in the next works of the authors.

In conclusion, it should be noted that the developed methodological approach enables to assess the degree of reaction of certain types of economic activities to the impact on the regional and national economic systems ofshocks external "impulses". At the same time the values of the coefficients indicating the elasticity of the studied endogenous parameters as a result of the current and future corrections to the expectations of economic agents in many respects may indicate the level of receptivity of certain types of economic activities to various effects. Thus, we can assess the current and future levels of competitiveness, not only of the regional sectoral types of activities, but also the entire region in general. 


\section{Acknowledgement}

The publication is prepard in the framework of the research project N15-32-01353 supported by the Russian Foundation for Humanities.

\section{References}

Gafurov, I.R. (2012) The analysis of gaps of competitiveness of the productions of petrochemical cluster of the Republic of Tatarstan. Kazan: Kazan University.

Aksyanova, A.V., Elshin, L.A. \& Shakirova, A.I. (2011) Assessment of business activity in the region with use of aggregate anticipatory index, Vestnik of Kazan Engineering University, 8.

Aksyanova, A.V. \& Shakirova, A.I. (2009). Prognostication of business activity in the Republic of Tatarstan with use of the system of anticipatory indicators. Collection of scientific papers of MESI.

Granberg, A.G. \& Miheeva, N.N. (2009). Influence of the world crisis on the strategy of the spatial social and economic development of the Russian Federation, Region: economy and sociology, 4, 69-101.

Report of results and principle directions of activities of the Industry and Trade Ministry of the Republic of Tatarstan for 2010 from http://mpt.tatarstan.ru/rus/info.php?id=122423

Report of results and principle directions of activities of the Industry and Trade Ministry of the Republic of Tatarstan for 2011 from http://mpt.tatarstan.ru/rus/info.php?id=122423

Report of results and principle directions of activities of the Industry and Trade Ministry of the Republic of Tatarstan for 2012 from http://mpt.tatarstan.ru/rus/info.php?id=122423

Ermolaeva, O.P. \& Noskova, E.P. Index of social mood of the population of Russia: methodology, empirical research. «Russia and modern world», 3(80), 58-72.

Ermolaeva, O.P., Safiullin, M.R. \& Noskova, E.P. (2013). The competitiveness of the oil and gas sector of the Republic of Tatarstan: a sociological interpretation. «Mercury of SGSEU», 5.

Kondratiev, N.D. (2002). Large cycles of conjuncture and the theory of foresight. Selected Works. Moscow: Economy.

Porter, M.E. (2000). Competition. St.Petersburg: Publishing house «Viliams».

Safiullin, A.R. (2011). Competitive advantages (territorial-sectoral level). Germany: LAPLAMBERT Academic Publishing GmbH\&Co. KG.

Safiullin, A.R. \& Elshin, L.A. (2014). Assessment of the competitiveness of the industrial profile of the Republic of Tatarstan in the Volga Federal District. Economic Mercury of the Republic of Tatarstan, 2, 5-10.

Safiullin, L.A., Safiullin, A.R. \& Haziahmetov, B.Z. (2011). Structural study of the competitiveness of the Republic of Tatarstan (monography). Kazan: Kazan university press.

Sergeev, P. B. (2010). Sectoral aspects of Russia's entry into the World Trade Organization (by the example of copper subsector). PhD thesis. Ekaterinburg

Tokarev, A.H. The innovative development of Russian oil and gas sector: strategy and tactics, the preconditions and effects. Retrieved September, 302013 from http://law.admtyumen.ru/noframe/nic?d\&nd=466201944.

Shirov, A.A., Gusev,M.S., Yantovsky, A.A. \& Potapenko, V.V. (2012). Long-term development of the Russian economy and the problem of efficiency of the labor resources use, Problems of Forecasting, 1.

Age shall weary them. The productivity challenge of the rich world's demography. The Economist, retrieved May, 11, 2013, from http://www.economist.com/news/finance-and-economics/21577414-productivity-challenge-rich-worlds-demography-age-shallweary-them

Brown, D.J. \& Earle, J.S. (2008). Employment Reallocation and Productivity Growth in Transition: an International; Comparative Analysis. UK, Edinburgh: Upjohn University for Employment Research.Safiullin, M. R., Safiullin, A. R., Elshin, L. A. \& Prygunova, M. I. (2014). Matrix Approach to Assessing Competitiveness of Regions: From Methodology to Practice. Asian Social Science; $10,20$.

Safiullin, M. R., Elshin, L. A., Prygunova M. I. \& Galyavov A. A. (2013). Complex Analysis of Prospects of the Volga Federal District Regions Development: Methodology and Practice, World Applied Sciences Journal, 27(4), 508-511. 